\title{
Effect of Central Metals on Langmuir-Blodgett Monolayers of Phthalocyanines with Flexible Substituents*
}

\author{
Shungo Kojima \\ Department of Chemistry, Graduate School of Science, \\ The University of Tokyo, Hongo 7-3-1, Tokyo 113-0033, Japan \\ Tomoteru Fukumura and Tetsuya Hasegawa ${ }^{\dagger}$ \\ Department of Chemistry, Graduate School of Science, \\ The University of Tokyo, Hongo 7-3-1, Tokyo 113-0033, Japan, \\ JST-CREST, and \\ Kanagawa Academy of Science and Technology (KAST), Kawasaki 213-0012, Japan
}

(Received 29 December 2014; Accepted 2 March 2015; Published 11 April 2015)

\begin{abstract}
Langmuir-Blodgett (LB) monolayers of octaoctyloxy metallophthalocyanines $(M O O P c, M=\mathrm{Cu}, \mathrm{Zn})$ and copper tetra(tert-butyl) phthalocyanine were deposited on glass substrates. MOOPcs showed gradual increase in their surface pressure-area isotherms reflecting their flexible substituents. In spite of the similar molecular structure, $\mathrm{Cu}$ and $\mathrm{ZnOOPc}$ indicated different isotherms at lower pressure, manifested by the surface morphology. At high surface pressure, ZnOOPc monolayer became denser than $\mathrm{CuOOPc}$ monolayer, as was estimated by the optical absorption. These results represents that the central metals have a crucial effect on structures of LB monolayers. [DOI: $10.1380 /$ ejssnt.2015.155]
\end{abstract}

Keywords: Langmuir-Blodgett films; Monolayer; Atomic force microscopy; X-ray reflection; Visible/ultraviolet absorption spectroscopy

\section{INTRODUCTION}

Phthalocyanines are well-known important dye molecules, possessing high ultraviolet/visible optical absorption and good thermal stability, and are representative organic semiconductors with large $\pi$ conjugating system useful for e.g. photovoltaics [1], field effect transistors (FET) [2], gas sensing devices [3], mainly as thin film form. There are various ways to prepare the thin film such as vacuum deposition [4], spin coating [5], and Langmuir-Blodgett (LB) film deposition [6]. Among them, LB method is used to fabricate multilayers with well-defined molecular orientation and controllable thickness. For LB films of phthalocyanines, peripheral substituents such as bulky tert-butyl group and long alkyl chains are required to be dissolved in hydrophobic organic solvent, so that the solution can be spread at air-water interface. Under compression of the Langmuir film on the water, phthalocyanine molecules usually form columnar stacking assembly due to $\pi-\pi$ interaction between the macrocycles [7]. In order to control the molecular orientation in LB films, it would be effective to select proper peripheral substituents because characters of substituents such as length, flexibility, and hydrophilicity have crucial effects on molecular orientation at air-water interface, resulting in peculiar surface pressure-area isotherms ( $\pi-A$ curves) [8]. In addition, central metals of phthalocyanines also influence the orientation because of difference in metallomacrocycle-water interactions, i.e. the hydrophilicity [9].

\footnotetext{
* This paper was presented at the 7th International Symposium on Surface Science, Shimane Prefectural Convention Center $\mathrm{Ku}$ nibiki Messe), Matsue, Japan, November 2-6, 2014.

$\dagger$ Corresponding author: hasegawa@chem.s.u-tokyo.ac.jp
}

In this report, we fabricated LB monolayers of octaoctyloxy metallophthalocyanine ( $M O O P c$, central metal $M=$ $\mathrm{Cu}$ and $\mathrm{Zn}$ ) and copper tetra(tert-butyl) phthalocyanine $(\mathrm{CuTTBPc})$ as a reference. The former is representative phthalocyanine molecule containing flexible long hydrophobic substituents, whereas the latter is one of the phthalocyanines with rigid structure. The different substituent and central metals affected the molecular orientation in the LB monolayers, manifested by the surface morphology and optical absorption.

\section{EXPERIMENTAL}

CuTTBPc, CuOOPc and ZnOOPc (Sigma-Aldrich) were used without further purification. CuTTBPc, $\mathrm{CuOOPc}$, and $\mathrm{ZnOOPc}$ were dissolved in chloroform (Wako Chemical), where each concentration was $2.2 \times$ $10^{-4} \mathrm{M}, 9.0 \times 10^{-5} \mathrm{M}$, and $9.0 \times 10^{-5} \mathrm{M}$, respectively. Glass plates were used as substrates. The surface of substrates were made hydrophilic by immersion in $\mathrm{CH}_{3} \mathrm{OH}: \mathrm{HCl}$ aq followed by conc. $\mathrm{H}_{2} \mathrm{SO}_{4}$ aq, and were rinsed by ultrapure water. The LB equipment of USI Co. Ltd. was used. The substrate was dipped into ultrapure water. Each solution of the phthalocyanine was spread onto ultrapure water in the trough at $15-20^{\circ} \mathrm{C}$. After the evaporation of the solvent, the floating layer was compressed by two barriers at a rate of $2-3 \mathrm{~mm} / \mathrm{min}$. Surface pressure was kept at 3 or $20 \mathrm{mN} / \mathrm{m}$ for $15 \mathrm{~min}$ before deposition. LB monolayer was deposited by withdrawing the glass substrate at a rate of 0.4 and $2 \mathrm{~mm} / \mathrm{min}$ for $\mathrm{CuTTBPc}$ and $M O O P c$, respectively. The surface morphology of the films were measured by atomic force microscope in tapping mode using cantilevers with nominal spring constant of $28 \mathrm{~N} / \mathrm{m}$. Absorption spectra for ultraviolet-visible region of the films were measured in air. 

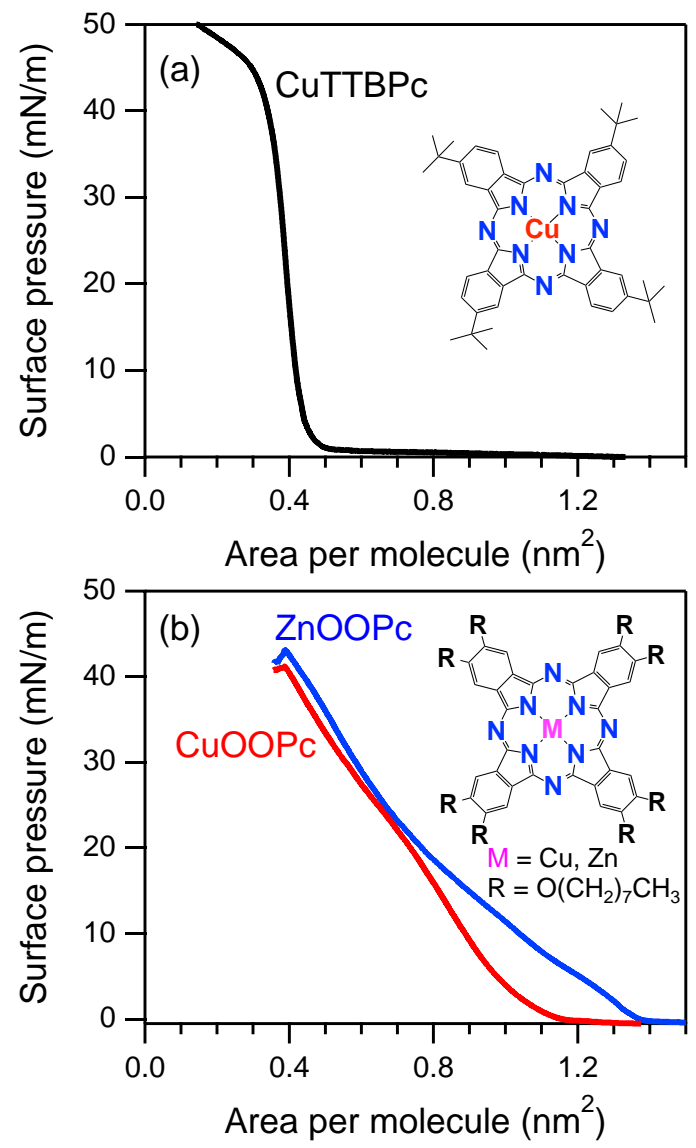

FIG. 1. Surface pressure-area isotherms for (a) CuTTBPc (a) and (b) $M$ OOPc $(M=\mathrm{Cu}$ and $\mathrm{Zn})$ monolayers. In inset each molecular structure is shown.

\section{RESULTS AND DISCUSSION}

Figure 1 shows $\pi$ - $A$ curves for monolayers of CuTTBPc (Fig. 1(a)) and $M \operatorname{OOPc}(M=\mathrm{Cu}, \mathrm{Zn})$ (Fig. 1(b)). The limiting areas were $0.44 \mathrm{~nm}^{2}, 1.04 \mathrm{~nm}^{2}$, and $1.33 \mathrm{~nm}^{2}$ for $\mathrm{CuTTBPc}, \mathrm{CuOOPc}$, and $\mathrm{ZnOOPc}$, respectively. $\pi-A$ curve of CuTTBPc increased abruptly around the limiting area, being consistent with previous study [10]. This small limiting area indicates an oblique coplanar molecular orientation with dense molecular packing [11]. In contrast, $\mathrm{CuOOPc}$ and $\mathrm{ZnOOPc}$ showed gradual increase in the $\pi$ - $A$ curves with significantly larger limiting area than that of CuTTBPc, which were larger than the size of phthalocyanine moiety $100 \AA^{2}$ [12]. This result represents relatively in-plane alignment of the molecules with small molecular packing density, originated from the eight long and flexible alkyl chains of MOOPcs. More quantitatively, the surface pressure of $\mathrm{ZnOOPc}$ started increasing at larger area than that of $\mathrm{CuOOPc}$. $\mathrm{CuOOPc}$ and $\mathrm{ZnOOPc}$ formed different assembly at the lower surface pressure. Hence, not only peripheral substituents but also central metals influenced the orientation and the molecular assembly in the Langmuir films. This result is probably due to the hydrophilicity of metallomacrocycle, i.e. the difference in coordination of water molecule to central metal [9]. On the other hand, both molecules

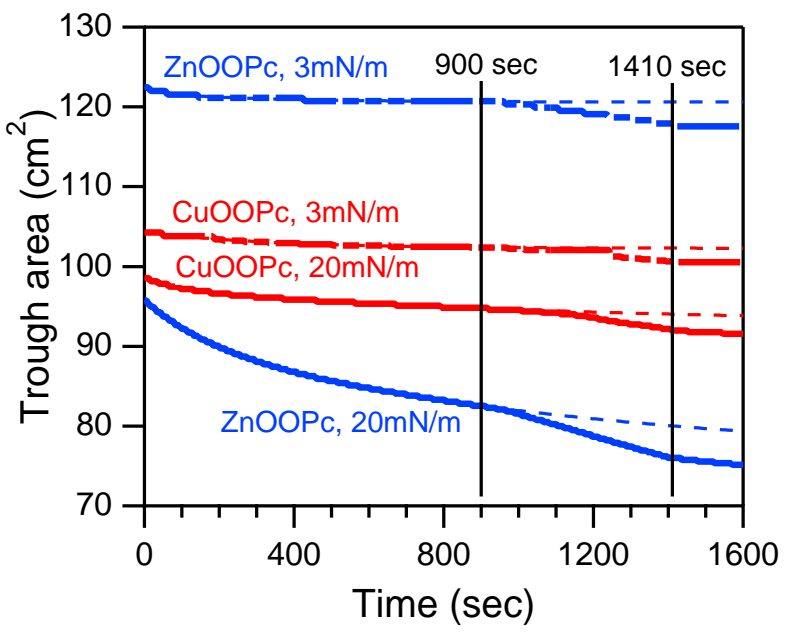

FIG. 2. Time evolution of the trough area after reaching prescribed surface pressure for $\mathrm{CuOOPc}$ and $\mathrm{ZnOOPc}$ monolayers. Dotted lines are fitting curves until withdrawing substrates.

showed similar $\pi$ - $A$ curves above the surface pressure of $20 \mathrm{mN} / \mathrm{m}$. This result suggests similar assembly of both molecules due to dominant intermolecular interaction between phthalocyanines over the coordination of water molecule, however, the detail orientations were different as described below.

Figure 2 shows time evolution of the trough area after reaching a set point of surface pressure, 3 or $20 \mathrm{mN} / \mathrm{m}$ for each monolayer. Surface pressure was kept for 900 sec, and then the vertically immersed glass substrate was withdrawn. Deposition was finished at 1410 sec. Among them, trough area of $\mathrm{ZnOOPc}$ at $20 \mathrm{mN} / \mathrm{m}$ decreased rapidly, indicating that the high surface pressure induced further compression to maintain the surface pressure. On the other hand, $\mathrm{CuOOPc}$ at $20 \mathrm{mN} / \mathrm{m}$ did not show such decrease in surface pressure. Accordingly, ZnOOPc monolayer became denser under further compression probably due to intermolecular $\pi$-ring attractive interaction. $\mathrm{ZnOOPc}$ monolayer is expected to form more compressed in-plane zigzag assembly than $\mathrm{CuOOPc}$ molecules [11].

Figure 3 shows atomic force microscope images for the monolayers. Surface morphology of CuTTBPc monolayer showed small circular aggregates (Fig. 3(a)) probably due to the high surface pressure [12]. The film thickness of $2.1 \mathrm{~nm}$ evaluated from $\mathrm{x}$-ray reflectivity was close to the in-plane diagonal size of CuTTBPc, $1.95 \mathrm{~nm}$ [13]. This result supports the oblique coplanar orientation of $\mathrm{CuT}$ TBPc monolayer. $M O O P c$ monolayers showed variable morphology depending on surface pressure and central metals. For the surface pressure of $3 \mathrm{mN} / \mathrm{m}, \mathrm{CuOOPc}$ monolayer showed flat and homogeneous surface representing uniform distribution of molecules as shown in Fig. 3(b). On the other hand, the $\mathrm{ZnOOPc}$ film for the same surface pressure showed the assembly of islands with partial coverage as shown in Fig. 3(d). The observed difference in the surface morphology is attributed to different molecular orientation, because each area at surface pressure of $3 \mathrm{mN} / \mathrm{m}$ was significantly different as seen in Fig. 1(b). The height of $\mathrm{ZnOOPc}$ islands was 

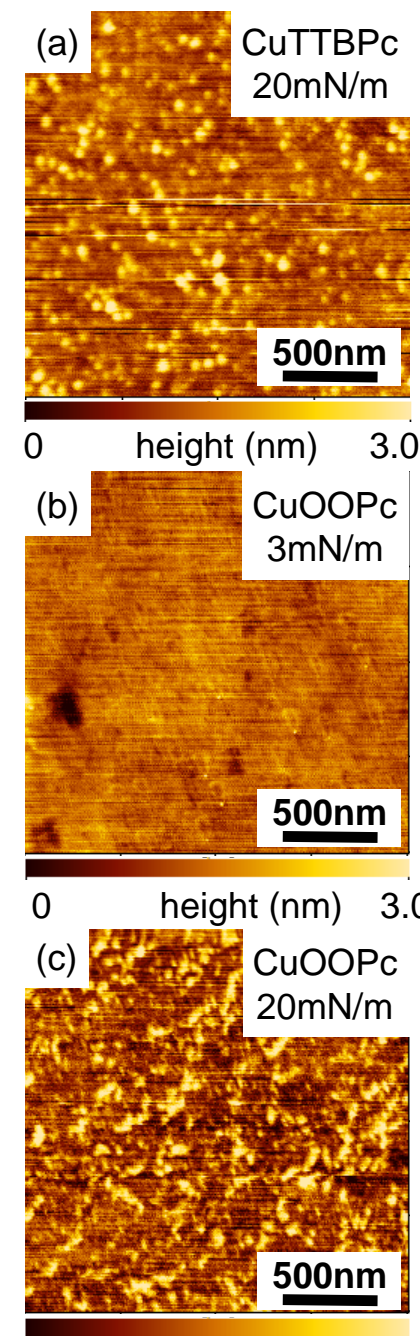

0

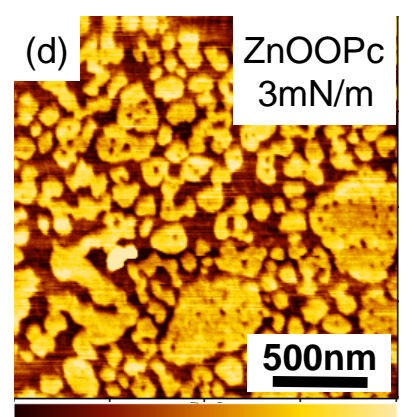

height $(\mathrm{nm}) \quad 3.0$

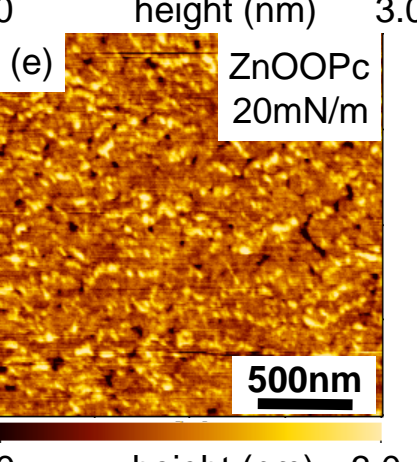

height $(\mathrm{nm}) \quad 3.0$

FIG. 3. AFM images of LB monolayers deposited at different surface pressures. (a) CuTTBPc at $20 \mathrm{mN} / \mathrm{m}$. CuOOPc (b) at $3 \mathrm{mN} / \mathrm{m}$ and (c) at $20 \mathrm{mN} / \mathrm{m}$. ZnOOPc (d) at $3 \mathrm{mN} / \mathrm{m}$ and (e) at $20 \mathrm{mN} / \mathrm{m}$.

about $1.6 \mathrm{~nm}$, which is much smaller than the lateral size of $\mathrm{ZnOOPc}$ molecule containing long octyloxy chains. Hence, the islands are the assembly of in-plane zigzag molecular monolayer, owing to hydrophilic nature of central metal Zn. For the surface pressure of $20 \mathrm{mN} / \mathrm{m}$, both films showed similar fibril structure (Figs. 3(c) and (e)).

Figure 4 shows UV-vis absorption spectra of LB monolayers. In comparison with $\mathrm{CuTTBPc}$ monolayer, the absorbance of $\mathrm{CuOOPc}$ and $\mathrm{ZnOOPc}$ monolayers was smaller because of the lower packing density of the molecules. For $\mathrm{CuOOPc}$ monolayers, the absorbance was slightly increased with increasing surface pressure. This result suggests that slight increase in the packing density. On the other hand, ZnOOPc showed different tendency. For the surface pressure of $3 \mathrm{mN} / \mathrm{m}$, the absorbance was the smallest reflecting nearly in-plane molecular orientation of $\mathrm{ZnOOPc}$ molecules with partial coverage (Fig. 3(d)), as was supported by the significantly larger limiting area at the onset of surface pressure (Fig. 1(b)). For the surface pressure of $20 \mathrm{mN} / \mathrm{m}$, how-

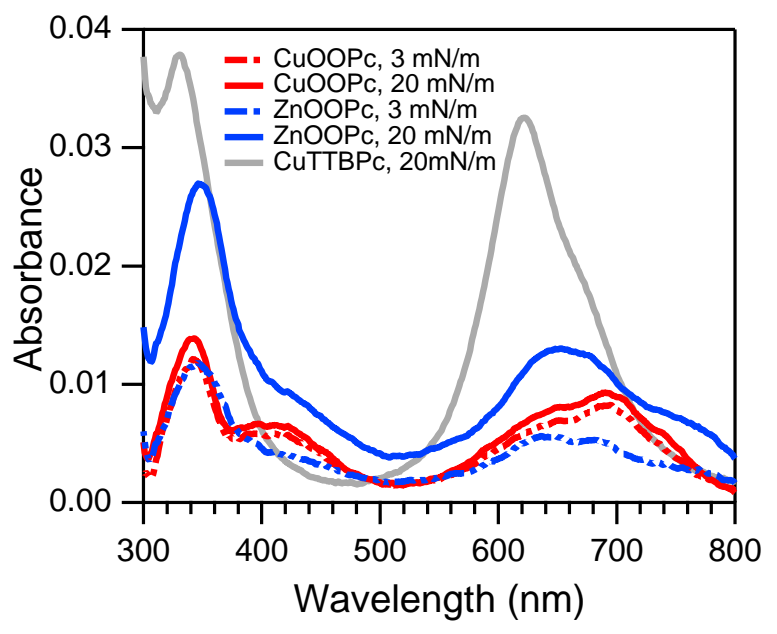

FIG. 4. Absorption spectra of LB monolayers deposited at different surface pressures.

ever, the absorbance was nearly doubled, probably due to the significantly compressed zigzag assembly by further compression during keeping the surface pressure (Fig. 2). $\mathrm{ZnOOPc}$ monolayer at $3 \mathrm{mN} / \mathrm{m}$ has two absorbance peaks at $647 \mathrm{~nm}$ and $682 \mathrm{~nm}$, while the monolayer at $20 \mathrm{mN} / \mathrm{m}$ has only one peak at $654 \mathrm{~nm}$. The high surface pressure induced dense packing of $\mathrm{ZnOOPc}$ molecules. Consequently, Q-band of ZnOOPc at $20 \mathrm{mN} / \mathrm{m}$ showed blueshift possibly due to the intermolecular interaction [14]. On the other hand, both absorption spectra for $3 \mathrm{mN} / \mathrm{m}$ and $20 \mathrm{mN} / \mathrm{m}$ show almost same shape for CuOOPc representing the similar molecular orientations irrespective of the surface pressure.

\section{CONCLUSIONS}

We investigated effects of surface pressure and central metal on $\mathrm{LB}$ monolayers of $\mathrm{CuOOPc}$ and $\mathrm{ZnOOPc}$. At the low surface pressure, $\mathrm{CuOOPc}$ and $\mathrm{ZnOOPc}$ monolayers formed in-plane zigzag assembly, in which $\mathrm{ZnOOPc}$ monolayer was more close to in-plane orientation due to the higher hydrophilicity of metallomacrocycle. At the high surface pressure, $\mathrm{ZnOOPc}$ monolayer formed more compressed zigzag assembly, while $\mathrm{CuOOPc}$ monolayer formed the similar assembly to that at the low surface pressure. These results represent that not only peripheral substituent but also central metal significantly affect LB assembly of phthalocyanine derivatives with flexible substituents.

\section{ACKNOWLEDGMENTS}

Parts of experiments were conducted in Center for Nano Lithography \& Analysis, The University of Tokyo, supported by MEXT, Japan. This research was in part supported by JSPS Grant-in-Aid for Scientific Research (26105002). 
[1] N. Wang, J. Yu, Y. Zang, J. Huang, and Y. Jiang, Solar Energ. Mater. Solar Cells 94, 263 (2010).

[2] J. A. J. Tejada, K. M. Awawdeh, J. A. L. Villanueva, J. E. Carceller, M. J. Deen, N. B. Chaure, T. Basova, and A. K. Ray, Org. Electron. 12, 832 (2011).

[3] L. Valli, Adv. Colloid Interface 116, 13 (2005).

[4] X. Lu, K. W. Hipps, X. D. Wang, and U. Mazur, J. Am. Chem. Soc. 118, 7197 (1996).

[5] M. J. Cook, D. A. Mayers, and R. H. Poynter, J. Mater. Chem. 5, 2233 (1995).

[6] M. A. Mohammed, P. Ottenbreit, W. Prass, G. Schnurpeil, and D. Wöhrle, Thin Solid Films 213, 285 (1992).

[7] D. R. Talham, Chem. Rev. 104, 5479 (2004).

[8] J.-P. Bourgoin, F. Doublet, S. Palacin, and M. Vandevyver, Langmuir 12, 6473 (1996).
[9] S. Fouriaux, F. Armand, O. Araspin, A. Ruaudel-Teixier, E. Maya, P. Vazquez, and T. Torres, J. Phys. Chem. 100, 16984 (1996).

[10] J. Souto, J. A. de Saja, M. I. Gobernado-Mitre, M. L. Rodriguez, and R. Aroca, Sensor Actuat. B 15-16, 306 (1993).

[11] A. Biadasz, B. Bursa, B. Barszcz, A. Bogucki, B. Laskowska, A. Graja, and D. Wróbel, Dyes Pigments 89, 86 (2011).

[12] Y. L. Emelyanov, V. V. Khatko, and A. A. Tomchenko, Synthetic Met. 79, 173 (1996).

[13] K. Xiao, Y. Liu, X. Huang, Y. Xu, G. Yu, and D. Zhu, J. Phys. Chem. B 107, 9226 (2003).

[14] Y. Qui, P. Chen, and M. Liu, Langmuir 24, 7200 (2008). 